(2)

\title{
Anaphylactic reaction following reversal of nondepolarizing muscle relaxant during general anesthesia: a case report
}

This article was published in the following Dove Press journal:

International Medical Case Reports Journal

8 August 2017

Number of times this article has been viewed

\section{Eunkyung Choi' \\ Saeyoung $\mathrm{Kim}^{2}$}

'Department of Anesthesiology and Pain Medicine, College of Medicine, Yeungnam University, Daegu, Republic of Korea; ${ }^{2}$ Department of Anesthesiology and Pain Medicine, School of Medicine, Kyungpook National University, Daegu, Republic of Korea
Correspondence: Saeyoung Kim Department of Anesthesiology and Pain Medicine, School of Medicine, Kyungpook National University, I30, Dongdeok-ro, Jung-gu, Daegu, 41944, Republic of Korea Tel +82532005545

Fax +82 534262760

Email saeyoungkim7@gmail.com
Abstract: An anaphylactic reaction during general anesthesia may cause fatal complications. Perioperative anaphylaxis can occur in response to different medications. To our knowledge, pyridostigmine or combination of pyridostigmine with glycopyrrolate-induced anaphylactic reaction during general anesthesia has not been reported. We report a case of a suspected anaphylactic reaction to these drugs. To reduce the risk of complicated perioperative anaphylactic events, prompt assessment and treatment are needed. Moreover, any undesirable exposure to confirmed allergens should be avoided as part of secondary prevention.

Keywords: anaphylaxis, emergency treatment, glycopyrrolate, pyridostigmine bromide

\section{Introduction}

Anaphylactic reactions during general anesthesia may cause fatal complications. Among various agents used in general anesthesia, neuromuscular blocking drugs, latex, antibiotics, and chlorhexidine are the most dominant causative agents, ${ }^{1}$ but any drug can provoke allergic reactions. However, to our knowledge, pyridostigmine or combination of pyridostigmine with glycopyrrolate-induced anaphylactic reaction during general anesthesia has not been reported.

Herein, we report a case of a suspected anaphylactic reaction to these drugs during general anesthesia. The patient provided written informed consent for the publication of this case report.

\section{Case report}

A 73-year-old man (weight $70 \mathrm{~kg}$, height $174 \mathrm{~cm}$ ) was scheduled to undergo elective phacoemulsification under general anesthesia. He was on medications for hypertension, diabetes mellitus, and chronic kidney disease. He had no known documented allergies or a history of surgery. Preoperative laboratory tests including electrocardiography and chest radiography did not reveal any abnormalities. He did not receive any premedication. General anesthesia was induced by intravenous administration of propofol $120 \mathrm{mg}$, alfentanil $500 \mu \mathrm{g}$, lidocaine $40 \mathrm{mg}$, and rocuronium bromide $50 \mathrm{mg}$, and he was intubated. Anesthesia was maintained using desflurane 4.0-6.0 volume\%, oxygen, and nitrous oxide. A single $500 \mathrm{mg}$ dose of cephalosporin was administered intravenously after the induction of anesthesia as a prophylactic antibiotic agent, after performing a routine intradermal skin test, the result of which was negative. The surgery was uneventful for 105 minutes. At the end of surgery, pyridostigmine $15 \mathrm{mg}$ 
and glycopyrrolate $0.4 \mathrm{mg}$ were administered intravenously to antagonize the residual neuromuscular blockade. When the patient regained consciousness, deep breathing was encouraged and extubation was performed. Immediately after extubation, the patient's electrocardiogram showed the development of premature ventricular contraction and bigeminy with a heart rate (HR) of 120 beats per minute (BPM). After immediate intravenous administration of lidocaine $60 \mathrm{mg}$, the premature ventricular contraction and bigeminy shortly returned to sinus rhythm, and the HR reduced to $80 \mathrm{BPM}$.

Approximately 5 minutes after the administration of pyridostigmine $15 \mathrm{mg}$ and glycopyrrolate $0.4 \mathrm{mg}$, his blood pressure (BP) dropped to 55/32 $\mathrm{mmHg}$, and the HR was 123 BPM. Intravenous phenylephrine $300 \mu \mathrm{g}$ was administered, followed by a rapid infusion of lactated Ringer's solution. However, the BP changed to 60/34 $\mathrm{mmHg}$ and the HR rose to 135 BPM. Invasive BP monitoring was established in the right radial artery. At that time, his face and trunk became erythematous, and he developed moderate skin rashes, but he showed no respiratory symptoms, such as bronchospasm, and all parameters of arterial blood gas analysis were within normal levels. With a suspected diagnosis of anaphylaxis, epinephrine $50 \mu \mathrm{g}$ was administered intravenously. Thereafter, his BP increased to $80 / 40 \mathrm{mmHg}$, but dropped to $50 / 30$ $\mathrm{mmHg}$ after 1 minute. To manage the refractory hypotension, continuous infusion of epinephrine was started at the rate of $0.04 \mu \mathrm{g} / \mathrm{kg} / \mathrm{min}$, and his BP remained above $85 / 45 \mathrm{mmHg}$. Methylprednisolone $125 \mathrm{mg}$ was also injected to prevent delayed anaphylactic reactions. Approximately 40 minutes after treatment, his BP stabilized at $110 / 80 \mathrm{mmHg}$. Therefore, the epinephrine infusion was tapered. He underwent cardiologic evaluations, including tests for cardiac enzymes and transthoracic echocardiography, the results of which were normal. He was discharged after 2 days without any further incidents.

Laboratory assessments were performed for serum tryptase, the levels of which had increased to $42.2 \mu \mathrm{g} / \mathrm{L}$ (normal range: $0-11 \mu \mathrm{g} / \mathrm{L}$ ) approximately 40 minutes after the onset of the anaphylactic episode, but decreased to $10 \mu \mathrm{g} / \mathrm{L}$ after 4 hours and to $3.5 \mu \mathrm{g} / \mathrm{L}$ after 24 hours. The level of total serum immunoglobulin (Ig) E had elevated to $211 \mathrm{kU} / \mathrm{L}$ (normal range: $0 \sim 87 \mathrm{kU} / \mathrm{L}$ ). To determine the possible allergens that caused the anaphylactic reaction, uniform skin tests were performed after 8 weeks. The skin-prick and intradermal tests (at titers of 1:1000 and 1:100) were negative for all agents (lidocaine, propofol, rocuronium, alfentanil, pyridostigmine, and glycopyrrolate), and the patient refused further provocation challenge tests for a definitive diagnosis.

\section{Discussion}

In the present case, the patient had an anaphylactic reaction to the intravenous administration of pyridostigmine and glycopyrrolate. This is the first report with an immunological investigation assuming pyridostigmine and/or glycopyrrolate to be the cause of the perioperative anaphylactic reaction.

Anaphylaxis is a lethal systemic hypersensitivity reaction that is primarily mediated by specific IgE antibodies on the mast cells and basophils in response to allergen exposure. ${ }^{2}$ Rarely, other immunologic mechanisms such as IgG, ${ }^{3}$ complement, ${ }^{4}$ or activation of the innate immune system ${ }^{5}$ might trigger anaphylaxis. The literature reports that the incidence of perioperative anaphylaxis is 1:6000-1:20000, ${ }^{6}$ and its mortality rate is $3 \%-6 \%{ }^{7}$ Anaphylactic reactions usually occur within a few minutes after the administration of possible allergens, and their clinical features show a general pattern in various body organ systems including the skin, respiratory tract, cardiovascular system, gastrointestinal tract, and central nervous system, even though these patterns vary among patients. ${ }^{8}$ In particular, cardiovascular symptoms are typical in elderly patients, while respiratory symptoms are typical in young patients. ${ }^{9}$ In the present case, intense cardiovascular instability, dysarrhythmia, and skin lesions acutely developed after the intravenous administration of pyridostigmine and glycopyrrolate for reversing residual muscle relaxation, and this suggests the possibility of an anaphylactic reaction.

Pyridostigmine is an anticholinesterase drug, which is used to reverse nondepolarizing neuromuscular blockades. During general anesthesia, some cases of anticholinesterase drug-related anaphylaxis have been reported, but most of them are associated with the use of neostigmine, ${ }^{10,11}$ and only one case related to pyridostigmine use has been published. ${ }^{12}$ Castellano et $\mathrm{a}^{12}$ reported that a 54-year-old woman had an anaphylactic reaction to the oral administration of pyridostigmine during the treatment of myasthenia gravis. However, a pyridostigmine-induced anaphylactic reaction during general anesthesia has not been reported.

Glycopyrrolate is a quaternary ammonium derivative used for blocking the muscarinic effects of anticholinesterase such as pyridostigmine, neostigmine, and pyridostigmine. To the best of our knowledge, no report of anaphylaxis related to glycopyrrolate has been published to date.

The diagnosis of anaphylaxis is primarily based on clinical symptoms; however, the results of laboratory tests such as those for serum tryptase or plasma histamine levels may be useful for confirming the diagnosis. ${ }^{13}$ Serum tryptase levels 
should be collected ideally in the first 3 hours after the anaphylactic event, and comparison of the value through serial monitoring might provide more improved sensitivity than does a single point measurement. ${ }^{14}$ Reddy et al $^{15}$ identified that serum tryptase levels correlate positively with the severity of an allergic reaction. In the present case, serum tryptase levels were obtained sequentially at 40 minutes, 4 hours, and 24 hours after the onset of the anaphylactic episode, and the values increased to $42.2 \mu \mathrm{g} / \mathrm{L}$ at 40 minutes after the event and decreased to normal levels at the subsequent time points. These laboratory results might provide a means for confirming the diagnosis of anaphylaxis.

In terms of risk assessment in patients who have a suspected anaphylaxis, identifying the potential triggering allergens is an important part of secondary prevention. A positive skin test to a relevant specific trigger or elevated allergen-specific IgE levels help confirm sensitization, but are not diagnostic of anaphylaxis because asymptomatic sensitization is common. ${ }^{13}$ Skin tests should be performed 3-4 weeks after the anaphylaxis event to allow for the recovery of mast cell releasability; if not, they may yield false-negative results. ${ }^{14}$ In some cases, confirmation of the causative allergens via uniform skin tests can be difficult because low-molecular-weight substances or metabolites of drugs are less likely to have an adequate antigenic feature to anaphylaxis. Therefore, if indicated, incremental challenge tests may be needed in a medically well-equipped health care setting. In the present case, the total serum $\operatorname{IgE}$ level increased to $211 \mathrm{kU} / \mathrm{L}$. Even though our skin-prick and intradermal tests (at titers of 1:1000 and 1:100) did not yield any clear evidence for an allergic reaction, considering the timing of injection of the drugs, clinical signs, and laboratory tests such as those for serum tryptase and $\operatorname{IgE}$ levels, pyridostigmine and/or glycopyrrolate was the most likely cause of the anaphylactic reaction. To identify the actual allergen, further incremental challenge tests $(1: 10$ or $1: 1)$ may be needed.

Prompt treatment is essential when anaphylaxis is suspected. This is because anaphylaxis may result in death despite rapid and adequate management; therefore, perioperative anaphylaxis remains a major concern for anesthesiologists. Epinephrine is the preferred medication for the treatment of anaphylaxis. ${ }^{16}$ Its action mechanisms include $\alpha 1$-adrenergic vasoconstrictive effect, $\beta 1$-adrenergic cardiac contractions, and $\beta 2$ effects involved in increased bronchodilatation and decreased release of tryptase and histamine. ${ }^{16}$ During anesthesia, even in hospitalized patients, delayed injection of epinephrine can be problematic because anaphylaxis can be difficult to diagnose, and this delayed injection may cause rather fatal complications including biphasic anaphylaxis. ${ }^{17}$ Biphasic anaphylaxis is a relapse phenomenon that usually occurs within 8 hours after the resolution of the first anaphylactic event despite no further exposure to the causative agents. ${ }^{18}$ Moreover, an epinephrine overdose can lead to severe adverse reactions such as malignant hypertension or pulmonary edema, and therefore, timely and precautious usage of epinephrine is recommended. In addition to the administration of epinephrine for the management of perioperative anaphylaxis, H1-antihistamine and glucocorticoid can be used as adjuvant medications even though these are not the first-line treatment for acute anaphylactic episodes. ${ }^{13}$

\section{Conclusion}

Perioperative anaphylaxis can occur in response to any medication including pyridostigmine and/or glycopyrrolate. To reduce the risk of disastrous anaphylactic events during the perioperative period, prompt assessment and treatment are needed, and any undesirable exposure to confirmed allergens should be avoided as part of secondary prevention.

\section{Disclosure}

The authors report no conflicts of interest in this work.

\section{References}

1. Mertes PM, Tajima K, Regnier-Kimmoun MA, et al. Perioperative anaphylaxis. Med Clin North Am. 2010;94(4):761-789, xi.

2. Laxenaire MC. [Epidemiology of anesthetic anaphylactoid reactions. Fourth multicenter survey (July 1994-December 1996)]. Ann Fr Anesth Reanim. 1999;18(7):796-809. French.

3. Cheifetz A, Smedley M, Martin S, et al. The incidence and management of infusion reactions to infliximab: a large center experience. $\mathrm{Am}$ J Gastroenterol. 2003;98(6):1315-1324.

4. Kishimoto TK, Viswanathan K, Ganguly T, et al. Contaminated heparin associated with adverse clinical events and activation of the contact system. N Engl J Med. 2008;358(23):2457-2467.

5. Khodoun M, Strait R, Orekov T, et al. Peanuts can contribute to anaphylactic shock by activating complement. JAllergy Clin Immunol. 2009;123(2): 342-351.

6. Poulos LM, Waters AM, Correll PK, Loblay RH, Marks GB. Trends in hospitalizations for anaphylaxis, angioedema, and urticaria in Australia, 1993-1994 to 2004-2005. J Allergy Clin Immunol. 2007;120(4): 878-884.

7. Lin RY, Anderson AS, Shah SN, Nurruzzaman F. Increasing anaphylaxis hospitalizations in the first 2 decades of life: New York State, 1990-2006. Ann Allergy Asthma Immunol. 2008;101(4):387-393.

8. Simons FE. Anaphylaxis: recent advances in assessment and treatment. J Allergy Clin Immunol. 2009;124(4):625-636; quiz 637-628.

9. Tejedor Alonso MA, Moro Moro M, Mugica Garcia MV, et al. Incidence of anaphylaxis in the city of Alcorcon (Spain): a population-based study. Clin Exp Allergy. 2012;42(4):578-589.

10. Seed MJ, Ewan PW. Anaphylaxis caused by neostigmine. Anesthesia. 2000;55(6):574-575. 
11. Hermite L, Louvier N, Hilaire P, Orry D, Seltzer S, Collet E. Neostigmine induced anaphylaxis in the wake of surgery. Anesth Crit Care Pain Med. 2015;34(2):109-111.

12. Castellano A, Cabrera M, Robledo T, et al. Anaphylaxis by pyridostigmine. Allergy. 1998;53(11):1108-1109.

13. Simons FE, Ardusso LR, Bilo MB, et al. 2012 Update: World Allergy Organization Guidelines for the assessment and management of anaphylaxis. Curr Opin Allergy Clin Immunol. 2012;12(4):389-399.

14. Simons FE, Frew AJ, Ansotegui IJ, et al. Risk assessment in anaphylaxis: current and future approaches. JAllergy Clin Immunol. 2007;120(Suppl 1): S2-S24.
15. Reddy JI, Cooke PJ, van Schalkwyk JM, Hannam JA, Fitzharris P, Mitchell SJ. Anaphylaxis is more common with rocuronium and succinylcholine than with atracurium. Anesthesiology. 2015;122(1):39-45.

16. Irani AM, Akl EG. Management and prevention of anaphylaxis. F1000Research. 2015;22:4

17. Sampson HA, Mendelson L, Rosen JP. Fatal and near-fatal anaphylactic reactions to food in children and adolescents. $N$ Engl $J$ Med. 1992;327(6):380-384.

18. Tole JW, Lieberman P. Biphasic anaphylaxis: review of incidence, clinical predictors, and observation recommendations. Immunol Allergy Clin North Am. 2007;27(2):309-326, viii.

\section{Publish your work in this journal}

The International Medical Case Reports Journal is an international, peer-reviewed open-access journal publishing original case reports from all medical specialties. Previously unpublished medical posters are also accepted relating to any area of clinical or preclinical science. Submissions should not normally exceed 2,000 words or
4 published pages including figures, diagrams and references. The manuscript management system is completely online and includes a very quick and fair peer-review system, which is all easy to use. Visit $\mathrm{http}: / / \mathrm{www}$.dovepress.com/testimonials.php to read real quotes from published authors.

Submit your manuscript here: https://www.dovepress.com/international-medical-case-reports-journal-journal 